\title{
SECTORAL INFLATION PERSISTENCE, MARKET CONCENTRATION AND IMPERFECT COMMON KNOWLEDGE
}

\author{
Ryo Kato \\ Tatsushi Okuda \\ Takayuki Tsuruga
}

March 2020

The Institute of Social and Economic Research

Osaka University

6-1 Mihogaoka, Ibaraki, Osaka 567-0047, Japan 


\title{
Sectoral inflation persistence, market concentration and imperfect common knowledge*
}

\author{
Ryo Kato† Tatsushi Okuda; and Takayuki Tsuruga ${ }^{\S}$
}

March 25, 2020

\begin{abstract}
Previous studies have stressed that inflation dynamics exhibit a substantial dispersion across sectors. Using US producer price data, we present evidence that sectoral inflation persistence is negatively correlated with market concentration, which is difficult to reconcile with the prediction of the standard model of monopolistic competition. To explain the data, we incorporate imperfect common knowledge into the monopolistic competition model introduced by Melitz and Ottaviano (2008). In the model, strategic complementarity among firms increases as market concentration decreases. Because higher strategic complementarity generates greater inflation persistence, our model successfully replicates the observed negative correlation between inflation persistence and market concentration across sectors.
\end{abstract}

JEL Classification: E31, D40, L16

Keywords: Imperfect common knowledge, Inflation persistence, Market concentration

*We thank Ryan Chahrour, Jeffrey Fuhrer, Mark Gertler, Yukinobu Kitamura, John McDermott, Benjamin Moll, Satoshi Nakada, Taisuke Nakata, Kiyohiko G. Nishimura, Mototsugu Shintani, Takeki Sunakawa, Yuki Teranishi, Takashi Ui, Rosen Valchev, and Toshiaki Watanabe for their helpful comments and discussions. Kato and Tsuruga gratefully acknowledge the financial support of the Joint Usage/Research Center at the Institute of Social and Economic Research (ISER) and Grants-in-Aid for Scientific Research (15H05729, 15H05728, 18K01684, and 19K23219). This paper was previously circulated as "Market Concentration and Sectoral Inflation Under Imperfect Common Knowledge." The views expressed in this paper are those of the authors and do not necessarily reflect the official views of the Bank of Japan.

${ }^{\dagger}$ Graduate School of Public Policy, University of Tokyo

${ }^{\ddagger}$ Research and Statistics Department, Bank of Japan

$\S$ Institute of Social and Economic Research, Osaka University; CAMA. Correspondance to: Institute of Social and Economic Research, Osaka University 6-1 Mihogaoka, Ibaraki, Osaka 567-0047, Japan. E-mail address: tsuruga@iser.osaka-u.ac.jp 


\section{Introduction}

Inflation has long been a cornerstone issue in monetary economics. Researchers considered disaggregate inflation at the industry level (hereafter, sectoral inflation) as a fundamental building block for aggregate inflation dynamics. Not surprisingly, sectoral inflation dynamics exhibit substantial heterogeneity across industries. For instance, Leith and Malley (2007) and Imbs et al. (2011) estimate sector-level Phillips curves and conclude that sectoral inflation dynamics are significantly dispersed. ${ }^{1}$ In other work, Boivin et al. (2009, hereafter BGM) and Altissimo et al. (2009) incorporate sector-specific shocks in their models to replicate the heterogeneous responses of sectoral prices and inflation to common shocks. Further, Bils and Klenow (2004) report negative correlation between inflation persistence and the degree of price stickiness as a puzzle unaccounted for by the Calvo model. Clark (2006) reveals little correlation between inflation persistence and price stickiness across sectors. Together, these previous studies suggest that substantial heterogeneity in sectoral inflation dynamics remains an important challenge.

This paper explores factors that give rise to the substantial dispersion in sectoral inflation persistence. We focus on the relationship between sectoral inflation persistence and market concentration. Using US producer price index (PPI) data, we reveal that sectoral inflation persistence, as measured by the first-order autocorrelation, exhibits a negative correlation with market concentration. To illustrate, Figure 1 provides a scatter plot of the first-order autocorrelation against the Herfindahl-Hirschman Index (HHI) across 145 US manufacturing sectors. $^{2}$ As shown, while the scatter plot is somewhat noisy, the regression line indeed suggests a negative correlation.

The canonical models of monopolistic competition under constant elasticity of substitution (CES) preferences fail to reconcile the observed negative correlation. The standard

\footnotetext{
${ }^{1}$ See also Byrne et al. (2013) and Luengo-Prado et al. (2018).

${ }^{2}$ Later, we use the four-firm concentration ratio (C4 ratio), the preferred measure in Bils and Klenow (2004) and BGM, as an alternative. We show that our main finding is robust across the two measures of market concentration.
} 
Dixit-Stiglitz monopolistic competition model implicitly assumes that market concentration is invariant. Notably, the quadratic preferences proposed by Melitz and Ottaviano (2008, hereafter MO) allow the degree of market concentration to vary across sectors in the otherwise standard model of monopolistic competition. ${ }^{3}$ Here, for convenience, we refer to this setup as the MO model. In the MO model, if market concentration is high, firms set their prices with positive markup as in the standard Dixit-Stiglitz model. The MO model can also represent a perfectly competitive market as a limiting case where market concentration is at its lowest. Nevertheless, the flexible preferences in the MO model are not sufficient: inflation persistence has no correlation with market concentration.

We find that incorporating information rigidity into the MO model can account for the observed negative correlation. The information rigidity that we consider is imperfect common knowledge as developed by Woodford (2003) and Morris and Shin (2002). As demonstrated by Woodford (2003), among others, higher strategic complementarity under imperfect common knowledge generates greater inflation persistence. ${ }^{4}$ We apply this powerful mechanism to the MO model where strategic complementarity negatively comoves with market concentration. ${ }^{5}$

Our model closely relates to recent studies that emphasize the importance of market structure on firms' pricing decisions. These studies successfully generate endogenous markups that increase with the degree of market concentration, as in MO. However, the motivations differ. For example, Sbordone (2010) discusses the effects of increases in traded goods on the slope of the Phillips curve, while Afrouzi (2019) argues that strategic complementarity in an oligopolistic market enhances the nonneutrality of money. Lastly, Amiti et al. (2019) develop the model of incomplete pass-through in which endogenous markups vary with the pricing of firms in an oligopolistic market.

\footnotetext{
${ }^{3}$ Vives (1990) and Ottaviano et al. (2002) consider similar quadratic utility functions in the context of trade theory.

${ }^{4}$ See also Fukunaga (2007), Nimark (2008), and Angeletos and La'O (2009). Crucini et al. (2015) and Candian (2019) apply a model with imperfect common knowledge to examine the persistence of real exchange rates.

${ }^{5}$ Sbordone (2007) discusses the effects of variable market concentration on strategic complementarities using Kimball's (1995) preferences. In a similar spirit, our model relies on MO's preferences.
} 
The remainder of the paper is organized as follows. Section 2 discusses the empirical evidence. Section 3 introduces the basic model with comparative statistics. Section 4 presents the numerical results in the extended model. Section 5 discusses the Calvo model in the context of our empirical findings. Section 6 concludes.

\section{Evidence}

\subsection{Data}

We use US (seasonally adjusted) producer prices at the six-digit level of the North American Industry Classification System (NAICS) code to explore the empirical characteristics of sectoral inflation persistence and market concentration. We focus on the PPI rather than consumer price index (CPI) because we examine the linkage between inflation persistence of a particular good/service and the degree of market concentration of that sector. To inspect the linkage, the item classification of the PPI is matched with the industry (sector) classification of the market concentration data taken from the 2007 Economic Census. In addition, the PPI is more convenient than the CPI because its classification and that of the 2007 Economic Census can be fully matched in terms of items and industries through the same industry classification (NAICS) codes.

For the data sources, we use two PPI datasets. The first dataset is from BGM. ${ }^{6}$ The dataset includes the PPI prices of 152 items at monthly frequency, and the sample period runs from February 1976 to June 2005. The second dataset covers a more recent period running from January 2004 to February 2017. We include 272 manufacturing sectors and 111 nonmanufacturing sectors in this second dataset, which we call the extended dataset.

With respect to the measurement of market concentration, two indicators are available. The first is the classic Herfindahl-Hirschman Index (HHI). The second indicator of market

${ }^{6}$ The data are available at the American Economic Association website,
https://www.aeaweb.org/articles?id=10.1257/aer.99.1.350


concentration is the share of the top-four largest firms in the sector, often referred to as the C4 ratio. ${ }^{7}$ Both are from the 2007 Economic Census. While the C4 ratio is available for all sectors, the HHI is available only for manufacturing sectors.

Table 1 suggests that inflation persistence exhibits substantial dispersion across sectors in both datasets. Here, we define the first-order autocorrelation of the difference in log prices in a particular industry (i.e., industry-level aggregate price) as our measure of sectoral inflation persistence. ${ }^{8}$ For the within-industry comparison, we focus on manufacturers, i.e., the first and second columns in Table 1. The standard deviations of manufacturers are 0.19 and 0.23 in the two datasets, both of which are similarly large. In fact, the sectoral inflation persistence ranges from a maximum of 0.61 to a minimum of -0.44 in the BGM dataset and from 0.75 to -0.59 in the extended dataset. Compared with manufacturers, while the average is somewhat lower, the dispersion observed among nonmanufacturers is similarly significant as that for manufacturers. For example, the standard deviation for nonmanufacturers is 0.18 , which is close to that for manufacturers.

This considerable dispersion does not appear to be an artifact arising from idiosyncratic shocks in highly disaggregated data because each industry sector (at the NAICS six-digit level) includes, on average, 374 firms in the BGM dataset and 801 firms in the extended dataset. This large number of firms in each industry ensures that the influence of idiosyncratic shocks for individual firms is washed out at the industry level.

\section{$2.2 \quad$ Regressions}

We run regressions specifying sectoral inflation persistence as the dependent variable. The explanatory variables of interest are the indicators of market concentration, i.e., $H H I_{i}$ and

\footnotetext{
${ }^{7}$ Carlton (1986), Bils and Klenow (2004), and BGM all use the C4 ratio as a measure of market concentration.

${ }^{8}$ Furher (2011) discusses alternative measures of inflation persistence, including the first-order autocorrelation. BGM use the sum of all autoregressive (AR) coefficients including 13 lags. As a robustness check, we also use this alternative measure and confirm that our main finding, i.e., the negative correlation with market concentration, remains unchanged.
} 
$C 4_{i}$, where $i$ denotes the industry index. We also include additional explanatory variables to control for sector-specific shocks, which we discuss later in the section.

Our main finding is that in Tables 2 and 3 , all the estimated coefficients on the indicators of market concentration $\left(H H I_{i}\right.$ and $\left.C 4_{i}\right)$ are negative and statistically significant. In Table 2, columns (1-1) and (2-1) are the benchmark specifications, which include only $H H I_{i}$ as the explanatory variable. The estimated coefficients are -0.062 in specification (1-1) using the BGM dataset and -0.048 in specification (2-1) using the extended dataset. Alternative specifications include sector-specific controls, namely, the sample variance of the residuals of the AR(1) model, $\sigma_{i}^{2}$, and the sector dummies, DM1 and DM2. DM1 controls for food and textile industries (NAICS codes starting with 31) while DM2 controls for paper, wood and chemical industries (NAICS codes starting with 32). The control variables tend to be insignificant in the BGM dataset while they have significant explanatory power in the extended dataset. Nonetheless, the estimated coefficients on $H H I_{i}$ remain significant in all specifications. Table 3 provides the results where the $\mathrm{C} 4$ ratio is used as the market concentration indicator. The results are fairly similar to those in Table 2 using the HHI. Further, because we have data for nonmanufacturers in the extended dataset, we run a regression pooling both manufacturers and nonmanufacturers. The result based on the largest dataset is included in Table 4. The estimated coefficients on $C 4_{i}$ are insignificant for specifications (1) and (2), but significant at the $1 \%$ level for (3) and (4). These results suggest that the sector dummy controlling for manufacturers/nonmanufacturers is important. ${ }^{9}$

Quantitatively, the estimated coefficients in Table 2 suggest that if the HHI of one sector is 1,000 points higher than the cross-sectional average, the inflation persistence of that sector will be lower by $0.05-0.06$. These estimation results are quantitatively stable across the two datasets. In addition, the size of the estimated coefficients is comparable with the slope of

\footnotetext{
${ }^{9} \mathrm{We}$ also ran regressions including 19 industry dummies for manufacturers. The results indicate that the estimated coefficients on $C 4_{i}$ and $H H I_{i}$ remain broadly unchanged compared to those in Tables 2 and 3 . Moreover, to control for outliers stemming from idiosyncratic shocks as mentioned in Section 2.1, we run the regression using the subsamples of sectors with $C 4_{i} \leq 0.5$. This subsample analysisregression also detects the significant negative correlation similar to the main results. The details are available upon request.
} 
the regression line in Figure 1. A cursory look at the regression line suggests that inflation persistence decreases from around 0.2 to slightly below 0.1 against a range of the HHI from 0 to over 2,000 .

\section{The basic model}

In this section, we introduce the basic model, which describes firm's pricing behavior within a particular industry sector. Throughout this analysis, any variable without the index $j$ represents the aggregate (average) variable at the sector level. In contrast, variables indexed by $j$ denote the variables of individual firms. In parallel with the data discussed in Section 2, we continue to use the first-order autocorrelation as the measure of inflation persistence in our model analysis in Sections 3 and 4.

In the basic model, all firms are subject to a sector-level common shock to marginal cost that is assumed to be i.i.d. The i.i.d. assumption means that there is no extrinsic inflation persistence in the basic model and this helps crystallize the role of an endogenous mechanism that generates persistent inflation dynamics. Another benefit of inspecting the basic model is that it provides a simple analytical solution for the sectoral inflation in equilibrium. Later, in Section 4, we extend the model by incorporating both permanent and temporary shocks and numerically examine whether the property of the basic model remains the same.

\subsection{Preferences and technology}

The consumer maximizes utility $u$ by choosing a quantity of consumption of the indexed goods, $q_{t}(j)$ for $j \in[0, N]$ and the numeraire $q_{A}$. Specifically, we incorporate the quadratic preferences in MO into the utility function given by,

$$
u\left(q_{t}(j), q_{A}\right) \equiv \alpha \int_{j \in[0, N]} q_{t}(j) d j-\frac{\beta}{2} \int_{j \in[0, N]}\left(q_{t}(j)\right)^{2} d j-\frac{\gamma}{2}\left[\int_{j \in[0, N]} q_{t}(j) d j\right]^{2}+q_{A}
$$


We refer to $\alpha$ as the demand shifter because a larger $\alpha$ shifts out the demand for differentiated varieties. ${ }^{10}$ As $\gamma>0$ increases, the total demand for the differentiated goods compared with the numeraire decreases, amplifying the degree of competition among firms. The parameter $\beta \geq 0$ indicates the degree of love of variety. If $\beta=0$, the differentiated varieties are perfect substitutes and, hence, the consumer is interested only in the total consumption of the differentiated goods $\left(\int_{j \in[0, N]} q_{t}(j) d j\right)$. As $\beta$ increases, the consumer cares more about the consumption distribution across varieties.

The consumer budget constraint is given by,

$$
\int_{j \in[0, N]} q_{t}(j) p_{t}(j) d j+q_{A} \leq \bar{q}_{A},
$$

where $p_{t}(j)$ is the price of each good and $\bar{q}_{A}$ is the endowment of the numeraire which is exogenously provided with the same amount in each period. Note that this inequality always binds because of the monotonicity of the utility function $u$.

Given the preferences, we obtain the following linear demand function: ${ }^{11}$

$$
q_{t}(j)=\frac{\alpha h}{1+\beta h}-\frac{p_{t}(j)}{\beta}+\frac{p_{t}}{\beta(1+\beta h)},
$$

where the average price is given by,

$$
p_{t} \equiv \frac{1}{N} \int_{j \in[0, N]} p_{t}(j) d j,
$$

and $h \equiv(\gamma N)^{-1} \in[0, \infty]$. If we assume that $\gamma=10^{-4}$ and all firms are identical in size, $h$ can be interpreted as the HHI. ${ }^{12}$ We maintain these assumptions for the rest of the analysis.

We treat $h$ as the key indicator representing the degree of market concentration. A notable characteristic of (3) is that the sensitivity of the demand for good $j$ with respect to average

\footnotetext{
${ }^{10}$ We assume that $\alpha$ is constant for simplicity. As long as a time-varying $\alpha=\alpha_{t}$ follows the same stochastic process as that of $c_{t}$, our main results remain unchanged.

${ }^{11}$ See Appendix A for the derivation of the demand function given by (3).

${ }^{12}$ If $N$ is interpreted as the number of firms in a sector, the share of each firm is given by $(100 / N) \%$. Accordingly, the HHI is calculated as $(100 / N)^{2} \times N=10^{4} \times N$.
} 
price $p_{t}$ varies with $h$. This variable sensitivity is in sharp contrast to the case of CES utility where demand elasticity is assumed to be constant regardless of market concentration.

We turn to the firms' decision-making. There is a continuum of firms, indexed by $j \in$ $[0, N]$. Every firm operates under monopolistic competition, and the population of firms implies a mass of product varieties. Given marginal cost $c_{t}$, firm $j$ solves the following maximization problem,

$$
\max _{\left\{p_{t}(j)\right\}} \mathbb{E}_{j, t}\left[\left(p_{t}(j)-c_{t}\right) q_{t}(j)\right]
$$

subject to (3). Note that we assume $c_{t}$ is common for all firms in the sector. In (4) and hereafter, $\mathbb{E}_{j, t}[\cdot] \equiv \mathbb{E}\left[\cdot \mid \mathcal{H}_{t}(j)\right]$ denotes the expectations operator of firm $j$ conditional on information set $\mathcal{H}_{t}(j)$ available in period $t$, which we specify in the next section.

\subsection{Shocks and information structure}

In the basic model, $c_{t}$ follows a stochastic process given by,

$$
c_{t}=c_{t-1}+\varepsilon_{t}
$$

where, for simplicity, $\varepsilon_{t}$ is drawn from a Gaussian white noise process $\mathcal{N}\left(0, \sigma^{2}\right) .{ }^{13}$ Following Woodford (2003), we introduce private information regarding firms' costs with the aim of generating persistent inflation dynamics. Specifically, firms cannot observe $\left\{c_{s}\right\}_{s=0}^{t}$ in our model. Instead, firm $j$ receives private signal $x_{t}(j)$ given by,

$$
x_{t}(j)=c_{t}+\delta_{t}(j)
$$

where $\delta_{t}(j)$ is drawn from $\mathcal{N}\left(0, \tau^{2}\right)$, and recall that $c_{t}$ is identical across firms. With this information structure, firm $j$ 's information set $\mathcal{H}_{t}(j)$ includes $\left\{c_{0},\left\{x_{s}(j)\right\}_{s=0}^{t}\right\}$ and all the parameter values, including $h$. In a special case of perfect information where $\tau=0$, there

\footnotetext{
${ }^{13}$ In our model, we implicitly assume that $c_{0}$ is sufficiently large. This effectively allows us to ignore the possibility that $c_{t}<0$.
} 
is no private signal and, therefore, $\mathcal{H}_{t}(j)$ includes the entire history of firms' marginal costs, $\left\{c_{s}\right\}_{s=0}^{t}$ together with the parameter values.

\subsection{Equilibrium}

\subsubsection{Equilibrium under perfect information}

We first derive the equilibrium prices in the absence of a private signal. Plugging (3) into

the firm's profit function (4) and then taking derivatives with respect to $p_{t}(j)$ leaves the best-response function for a firm to choose its best price as follows.

$$
p_{t}(j)=\left(\frac{1}{2}-r\right) \alpha+r \mathbb{E}_{j, t}\left[p_{t}\right]+\frac{\mathbb{E}_{j, t}\left[c_{t}\right]}{2}
$$

where $r$ represents the degree of strategic complementarity, defined as,

$$
r(h) \equiv \frac{1}{2(1+\beta h)}
$$

Note that $r(h)$ is decreasing in $h$ in a monopolistically competitive market in the MO model. This is in sharp contrast to the Dixit-Stiglitz models under CES preferences.

In the case of no private signals, both $\mathbb{E}_{j, t}\left[p_{t}\right]=p_{t}(j)=p_{t}$ and $\mathbb{E}_{j, t}\left[c_{t}\right]=c_{t}$ hold for any $j$ because there is no heterogeneity across firms. Therefore, (7) can easily be solved for the equilibrium individual price $p_{t}(j)$ and the average price $p_{t}$ such that,

$$
p_{t}(j)=p_{t}=\kappa(h) \alpha+[1-\kappa(h)] c_{t},
$$

where $\kappa(h) \equiv \beta /\left(2 \beta+h^{-1}\right)$. Further, define the quasi-inflation rate as $\Delta p_{t} \equiv p_{t}-p_{t-1}$. This is now written as,

$$
\Delta p_{t}=[1-\kappa(h)] \varepsilon_{t}
$$

Note that sectoral inflation without private signals follows a white noise process inherited 
from $(5){ }^{14}$

\subsubsection{Equilibrium under imperfect common knowledge}

We turn to the case under imperfect common knowledge, that is, $\tau>0$ in (6). Here, we define average and higher-order expectations denoted recursively as,

$$
\overline{\mathbb{E}}_{t}^{1}[\cdot] \equiv \overline{\mathbb{E}}_{t}[\cdot] \equiv \frac{1}{N} \int_{j \in[0, N]} \mathbb{E}_{j, t}[\cdot] d j,
$$

and $\overline{\mathbb{E}}_{t}^{k+1} \equiv \overline{\mathbb{E}}_{t}\left[\overline{\mathbb{E}}_{t}^{k}[\cdot]\right]$ for every $k \geq 1$. With these notations, the average of $p_{t}(j)$ in $(7)$ over $j$ is now expressed as,

$$
p_{t}=\left(\frac{1}{2}-r\right) \alpha+r \overline{\mathbb{E}}_{t}^{1}\left[p_{t}\right]+\frac{1}{2} \overline{\mathbb{E}}_{t}^{1}\left[c_{t}\right]
$$

where $\overline{\mathbb{E}}_{t}^{1}\left[p_{t}\right]$ is no longer equal to $p_{t}$ in general because of the private signals. Plugging $p_{t}$ recursively into $\overline{\mathbb{E}}_{t}^{1}\left[p_{t}\right]$ on the right-hand side of (11) leaves the equilibrium price expressed as,

$$
p_{t}=\kappa(h) \alpha+[1-\kappa(h)](1-r) \sum_{k=1}^{\infty} r^{k+1} \overline{\mathbb{E}}_{t}^{k+1}\left[c_{t}\right] .
$$

We note that (12) is the same expression as that presented for general linear-quadratic problems by Morris and Shin (2002). This expression delivers a straightforward intuition about why persistent dynamics are generated in a sector where strategic complementarity $r$ is high. In (12), higher strategic complementarity places more weight on higher-order expectations of $c_{t}$, which generally adjust more slowly than lower-order expectations.

By simplifying (12), we now provide the explicit solution forms for $p_{t}$ in this basic model, namely, a linear combination of the past marginal costs such that,

$$
p_{t}=\kappa(h) \alpha+[1-\kappa(h)](1-\mu) \sum_{s=0}^{\infty} \mu^{s} c_{t-s} .
$$

\footnotetext{
${ }^{14}$ Hereafter, we refer to $\Delta p_{t}$ simply as inflation, instead of quasi-inflation.
} 
This equation implies,

$$
\Delta p_{t}=\mu \Delta p_{t-1}+(1-\kappa)(1-\mu) \varepsilon_{t}
$$

where $\mu$ is given by,

$$
\mu \equiv \frac{(1+\lambda) / \lambda-\sqrt{((1+\lambda) / \lambda)^{2}-4}}{2}
$$

where

$$
\lambda(r) \equiv \frac{\tau^{2}}{\tau^{2}+(1-r) \sigma^{2}}
$$

Note that $\Delta p_{t}$ follows an $\mathrm{AR}(1)$ process in (14) that can be compared with the i.i.d. white noise process given by (10) in the case of perfect information.

Note also that (15) indicates that $\lambda$ is monotonically increasing in both (i) the noisiness of private signals, $\tau^{2} / \sigma^{2}$ and (ii) the degree of strategic complementarity $r \in[0,1 / 2]$. In a limiting case where $r=0,1-\lambda$ coincides with the Kalman gain of steady-state Kalman filtering. ${ }^{15}$ This yields an economic intuition that if private signals are less precise (i.e., $\tau^{2} / \sigma^{2}$ is larger), firms place more weight $1-\lambda$ on the priors in their belief updating process, which generates slower dynamics for price and inflation, as documented in the information rigidity literature.

\subsection{Analytical results}

\subsubsection{Inflation persistence and market concentration: Comparative statics}

The explicit solution forms given by (10) and (14) reveal how inflation persistence varies depending on market concentration in our model. We continue to use the same measures of inflation persistence and market concentration as in Section 2. That is, $\operatorname{Corr}\left(\Delta p_{t}, \Delta p_{t-1}\right)$ denotes the first-order autocorrelation of inflation and $h$ represents the HHI as discussed in Section 3.1.

In the case of perfect information, (10) clearly indicates $\operatorname{Corr}\left(\Delta p_{t}, \Delta p_{t-1}\right)=0$ regardless

\footnotetext{
${ }^{15}$ We assume that $t$ is sufficiently large so that $\lambda(r)$ can be dealt with as a time-invariant parameter.
} 
of $h$. By contrast, (14) implies $\operatorname{Corr}\left(\Delta p_{t}, \Delta p_{t-1}\right)=\mu(\lambda)>0$ in the case of imperfect common knowledge. Notice that $\mu$ in (14) equals the first-order autocorrelation of inflation and, because $\lambda$ depends on $r$ as shown in (15), $\mu(\lambda(r))$ is increasing in $r$. Therefore, by applying the implicit function theorem and the chain rule, it can be confirmed that,

$$
\frac{\partial}{\partial h} \operatorname{Corr}\left(\Delta p_{t}, \Delta p_{t-1}\right)=\frac{d \mu}{d h}=\underbrace{\frac{d \mu}{d \lambda} \frac{d \lambda}{d r} \underbrace{\frac{d r}{d h}}_{M O}}_{I C K} \leq 0
$$

where $I C K$ and $M O$ point to the role of imperfect common knowledge and the prediction of the MO model, respectively. The derivation of (16) is provided in Appendix B.

The inequality in (16) indicates that incorporating imperfect common knowledge into the MO model is critical in explaining the negative correlation between inflation persistence and market concentration. The intuition behind (16) can be obtained via two steps. The first is to recall that strategic complementarity is higher in less concentrated markets $(d r / d h<0)$, as shown by (14). This negative correlation between strategic complementarity and market concentration is a unique feature of the MO model and is absent in monopolistic competition models under CES preferences. However, this feature is not sufficient to replicate the observed negative correlation between inflation persistence and market concentration as long as information is perfect.

The second step is to adopt the common mechanism in the models of imperfect common knowledge, which makes inflation persistence $\mu(\lambda(r))$ increasing in $r$. In markets where strategic complementarity is high, firms place more weight on their priors $(d \lambda / d r \geq 0)$ and less on private signals in the process of belief updating. With less information received via new signals, firms revise their prices more slowly $(d \mu / d \lambda \geq 0)$. 


\section{The extended model}

We now extend the basic model to examine whether our results concerning the negative relationship remain robust under a general marginal cost stochastic process.

\subsection{Shocks and information structure}

In the extended model, we allow for (i) deviations of the marginal cost from the stochastic trend, $\eta_{t}$ and (ii) the persistence of $\varepsilon_{t}$ parameterized by $\rho$. In particular, we assume the following stochastic process for $c_{t}$,

$$
\begin{aligned}
c_{t} & =\tilde{c}_{t}+\eta_{t}, \\
\tilde{c}_{t} & =\tilde{c}_{t-1}+\varepsilon_{t}, \\
\varepsilon_{t} & =\rho \varepsilon_{t-1}+e_{t},
\end{aligned}
$$

where $\eta_{t} \sim \mathcal{N}\left(0, \zeta^{2}\right)$ and $e_{t} \sim \mathcal{N}\left(0, \sigma^{2}\right)$ are Gaussian white noise processes. Recall that $\varepsilon_{t}$ was assumed to be i.i.d. and $c_{t}=\tilde{c}_{t}$ in the basic model. In the extended model, $c_{t}$ follows an autoregressive integrated moving average process, specifically, $\operatorname{ARIMA}(1,1,2)$ process, which generalizes the random walk process assumed for $c_{t}$ in the basic model.

The extended model can generate much richer inflation dynamics, consistent with the data. First, by introducing a temporary shock to $c_{t}$ (i.e., $\eta_{t}$ ), the model can replicate a wider range of levels of inflation persistence, including negative values. In fact, we can see from Table 1 that the minimum value of inflation persistence is negative. Second, our specification distinguishes between intrinsic and extrinsic inflation persistence, as emphasized in the literature. ${ }^{16}$ Note that $\rho$ in (19) represents the degree of extrinsic inflation persistence, because the persistence of $\Delta \tilde{c}_{t}$ is $\rho$ from (18) and (19). This specification contrasts sharply with that in the basic model in which the change in the marginal cost follows an i.i.d. process. In other words, the ARIMA(1,1,2) process allows the degree of extrinsic inflation persistence

\footnotetext{
${ }^{16}$ See Fuhrer (2010) for discussions on intrinsic and extrinsic persistence.
} 
to vary flexibly.

Under plausible dynamics of marginal cost, we numerically check the robustness of the negative correlation between inflation persistence and market concentration for different values of $\rho \in[0,1)$. We also examine to what extent the intrinsic inflation persistence generated by imperfect common knowledge amplifies the extrinsic inflation persistence embodied in the marginal cost.

Before we move to the numerical results, we note that the equilibrium price continues to be expressed as a linear combination of past marginal costs and $\alpha$ owing to the linear-quadratic nature of the problem. Specifically, it is given by,

$$
p_{t}=\kappa(h) \alpha+[1-\kappa(h)] \sum_{s=0}^{\infty} \phi_{t-s} c_{t-s}
$$

and, accordingly, inflation is,

$$
\Delta p_{t}=[1-\kappa(h)] \sum_{s=0}^{\infty} \phi_{t-s} \Delta c_{t-s}
$$

where each $\phi_{t-s}$ is a nonlinear function of $h$. Note that (20) generalizes (13) in the basic model. In what follows, we numerically compute $\phi_{t-s}$ to examine the inflation dynamics under various parameter values. ${ }^{17}$

\subsection{Numerical results}

\subsubsection{Inflation persistence and market concentration: Simulations}

As discussed in Section 3, we set $\gamma=10^{-4}$ so that $h$ can be interpreted as the HHI. For the other parameters, we set $\beta=10^{-3}, \sigma=1$, and $\zeta=1$ in the benchmark calibration. Given the size of the variance of the fundamentals (i.e., $\sigma^{2}$ and $\zeta^{2}$ ), we compute inflation persistence under a variety of $\rho$ as well as $\tau$, the precision of the private signal.

Figure 2 illustrates how inflation persistence varies against market concentration under a

\footnotetext{
${ }^{17}$ See Appendix $\mathrm{C}$ for details of the numerical methods.
} 
range of parameter sets such that $\rho \in\{0.0,0.2,0.7\}$ and $\tau \in\{0,1.5,2.0\}$. In all three panels, the lines for $\tau=0$ are flat against $h$, meaning that no intrinsic persistence is generated by the model under perfect information. The other lines for nonzero $\tau$ are downward sloping, which confirms the main result of the basic model under imperfect information.

Quantitatively, Figure 3 depicts that the size of the declines in inflation persistence predicted by the model is close to the data. The solid line plots the model's prediction of inflation persistence under $\rho=0$ and $\tau=2.0$, which decreases by 0.11 from 0.16 to 0.05 as the HHI increases from 0 to 2,000. ${ }^{18}$ Recall that in Section 2, we found that the estimated coefficients on $H H_{i}$ imply that an increase in HHI by 2,000 would reduce inflation persistence by $0.10-$ 0.12. This evidence can be reconfirmed by the dotted and dashed lines in Figure 3, which are the regression lines based on the coefficients in specifications (1-1) and (2-2) in Table 2. In particular, the dashed line indicates that inflation persistence decreases by 0.10 from 0.15 to 0.05 , along with the HHI increasing from 0 to 2,000 . The shaded area indicates the range of one standard deviation from the dashed regression line, which also shows that the model's prediction is in proximity to the regression result.

\subsubsection{Impulse response functions}

As an alternative presentation, we next rely on the impulse response analysis. Figure 4 depicts the impulse responses of inflation together with those of the changes in the marginal cost. We consider a permanent shock to $c_{t}$, namely, a unit increase in $e_{t}$ occurring in period $t=0$. In the figure, we set $\rho=0.7$ to generate highly persistent dynamics for expository purposes. The left panel plots the responses under perfect information $(\tau=0)$, while the right panel shows those under imperfect information with $\tau=5$. In both panels, the initial responses of inflation are standardized at 1.0 to facilitate the comparison of persistence across the two cases. Each panel depicts the responses of inflation in otherwise the same sectors

\footnotetext{
${ }^{18}$ The data presented in Section 2 show that the HHIs of $95 \%$ of sectors are less than 2,000 . We can confirm the range of the actual HHIs in Figure 1.
} 
with different degrees of market concentration (i.e., the solid line is for a less-concentrated market while the dotted line is for a highly concentrated market). Although the left panel appears to plot a single line, the three lines are overlaid.

The left panel confirms that if information is perfect, inflation dynamics exhibit no intrinsic persistence generated by the model regardless of market concentration. In contrast, in the right panel, the hump-shaped impulse responses of inflation indicate that inflation follows more persistent dynamics than the $\mathrm{AR}(1)$ process of the marginal cost $\left(\Delta c_{t}\right)$. This means that the intrinsic persistence generated by the imperfect information amplifies the extrinsic persistence in the shock process. Moreover, we emphasize that the solid line representing a less concentrated case $(h=1)$ exhibits more persistent dynamics than the dotted line for a more concentrated case $(h=2,000)$.

\section{An alternative approach: The Calvo model}

Apart from our arguments so far, some early studies emphasize the linkage between price stickiness and market concentration. If (i) the degree of price stickiness varies depending on market concentration and (ii) price stickiness increases inflation persistence, we can arrive at a reasonable hypothesis that can account for the observed correlation between inflation persistence and market concentration. Along with this argument, Carlton (1986) reports a positive correlation between the degree of price rigidity and market concentration. BGM argue that the price adjusts more sluggishly in more concentrated markets. ${ }^{19}$

In what follows, we explore the prediction of a Calvo model with standard CES preferences where the degree of price stickiness increases as market concentration rises. Let $\xi$ be the probability of no price changes. In the Calvo model, the (log-linearized) price index is a weighted average of the lagged price and the newly reset prices. Here, we maintain the same assumption as in our basic model that the (log of) marginal cost follows a random walk.

\footnotetext{
${ }^{19}$ However, Bils and Klenow (2004) conclude that market concentration does not have robust explanatory power for the degree of price stickiness as measured by the (in)frequency of price changes.
} 
Then, sectoral inflation follows an AR(1) process as, for instance, shown by Bils and Klenow (2004), such that,

$$
\Delta p_{t}=\xi \Delta p_{t-1}+(1-\xi) \varepsilon_{t}
$$

where $\xi$ now coincides with inflation persistence in the sector. Given the aforementioned findings by Carlton (1986) and BGM, (22) implies that the sectoral inflation persistence should positively correlate with market concentration. Namely,

$$
\frac{\partial}{\partial h} \operatorname{Corr}\left(\Delta p_{t}, \Delta p_{t-1}\right)=\frac{d \xi}{d h}>0
$$

which contradicts the empirical findings presented in Section 2.

The key to reconciling the seemingly contradicting predictions given by the Calvo model and our model presented in Sections 3 and 4 lies in the relationship between the degree of price stickiness and inflation persistence. Bils and Klenow (2004) report empirical facts that point to a negative correlation between the degree of price stickiness and inflation persistence across sectors. $^{20}$ Although the degree of price stickiness could positively correlate with market concentration, as shown by some early empirical studies, greater price stickiness in fact does not ensure higher inflation persistence. As suggested by studies of information rigidity models, inflation persistence cannot solely be explained by models of sticky prices. ${ }^{21}$

\section{Conclusion}

Many empirical studies have confirmed the role of information rigidities in firms' price-setting decisions. Our contribution to the literature on inflation dynamics is twofold. First, using US PPI data, we present evidence that sectoral inflation persistence is negatively correlated

\footnotetext{
${ }^{20}$ See Figures 2 and 3 in Bils and Klenow (2004). Table 4 also shows the correlation between (sectoral) inflation persistence and the frequency of price changes.

${ }^{21}$ Angeletos and La'O (2009) discuss the interaction of sticky prices, imperfect common knowledge, and strategic complementarity. Our model could be interpreted as a special case in their framework, but ours has an additional dimension whereby strategic complementarity systematically depends on market concentration following MO.
} 
with market concentration. Second, we find that strategic complementarity among monopolistically competitive firms decreases as market concentration increases in a model with imperfect common knowledge given quadratic preferences over the variety. Because of the varying strategic complementarity, our model can generate the observed negative correlation between inflation persistence and market concentration across sectors.

One caveat is that we used only PPI data in the empirical part of the analysis. Our model predictions could also be tested in retail markets, ideally using CPI or a personal consumption expenditure deflator combined with a coherent market concentration indicator. It is awaited that retail market structure data will be available to researchers in the near future.

\section{References}

[1] Afrouzi, Hassan, 2019, "Strategic Inattention, Inflation Dynamics and the NonNeutrality of Money," manuscript.

[2] Altissimo, Filippo, Benoit Mojon, and Paolo Zaffaroni, 2009, "Can Aggregation Explain the Persistence of Inflation?," Journal of Monetary Economics 56(2), pp. 231-241.

[3] Amiti, Mary, Oleg Itskhoki, and Jozef Konings, 2019, "International Shocks, Variable Markups and Domestic Prices" Review of Economic Studies 86(6), pp. 2356-2402.

[4] Angeletos, George-Marios, and Jennifer La'O, 2009, "Incomplete Information, HigherOrder Beliefs and Price Inertia," Journal of Monetary Economics 56, pp. S19-S37.

[5] Bils, Mark, and Peter J. Klenow, 2004, "Some Evidence on the Importance of Sticky Prices," Journal of Political Economy 112(5), pp. 947-985.

[6] Boivin, Jean, Marc P. Giannoni, and Ilian Mihov, 2009, "Sticky Prices and Monetary Policy: Evidence from Disaggregated US Data," American Economic Review 99(1), pp. $350-384$. 
[7] Byrne, Joseph P., Alexandros Kontonikas, and Alberto Montaggnoli, 2013, "International Evidence on the New Keynesian Phillips Curve Using Aggregate and Disaggregate Data," Journal of Money, Credit and Banking 45(5), pp. 913-932.

[8] Candian, Giacomo, 2019, "Information Frictions and Real Exchange Rate Dynamics," Journal of International Economics 116, pp. 189-205.

[9] Carlton, Dennis, 1986, "The Rigidity of Prices," American Economic Review 76(4), pp. $637-658$.

[10] Clark, Todd E., 2006, "Disaggregate Evidence on the Persistence of Consumer Price Inflation," Journal of Applied Econometrics 21(5), pp. 563-587.

[11] Crucini, Mario J., Mototsugu Shintani, and Takayuki Tsuruga, 2015, "Noisy Information, Distance and Law of One Price Dynamics across US Cities," Journal of Monetary Economics 74, pp. 52-66.

[12] Fuhrer, Jeffrey C., 2010, "Inflation Persistence," in Handbook of Monetary Economics 3A, B. M. Friedman and M. Woodford, eds., San Diego CA: North-Holland, pp. 423-486.

[13] Fukunaga, Ichiro, 2007, "Imperfect Common Knowledge, Staggered Price Setting, and the Effects of Monetary Policy," Journal of Money, Credit, and Banking 39(7), pp. 35-65.

[14] Imbs, Jean, Eric Jondeau, and Florian Pelgrin, 2011, "Sectoral Phillips Curves and the Aggregate Phillips Curve," Journal of Monetary Economics 58(4), pp. 328-344.

[15] Kimball, Miles S., 1995, "The Quantitative Analytics of the Basic Neomonetarist Model," Journal of Money, Credit and Banking, 27(4), pp. 1241-1277.

[16] Leith, Campbell and Jim Malley, 2007, "A Sectoral Analysis of Price-Setting Behavior in U.S. Manufacturing Industries," Review of Economics and Statistics, 89(2), pp. 335-342. 
[17] Luengo-Prado, María-José, Nikhil Rao, and Viacheslav Sheremirov, 2018, "Sectoral Inflation and the Phillips Curve: What Has Changed Since the Great Recession?," Economics Letters 172, pp. 63-68,

[18] Melitz, Marc J., and Gianmarco I. P. Ottaviano, 2008, "Market Size, Trade, and Productivity," Review of Economic Studies 75(1), pp. 295-316.

[19] Morris, Stephen, and Hyun S. Shin, 2002, "Social Value of Public Information," American Economic Review 92(5), pp. 1521-1534.

[20] Nimark, Kristoffer, 2008, "Dynamic Pricing and Imperfect Common Knowledge," Journal of Monetary Economics 55(2), pp. 365-382.

[21] Ottaviano, Gianmarco, Takatoshi Tabuchi, and Jacques-François Thisse, 2002, "Agglomeration and Trade Revisited," International Economic Review, 43(2), pp. 409-436.

[22] Sbordone, Argia M., 2007, "Globalization and Inflation Dynamics: The Impact of Increased Competition," in International Dimensions of Monetary Policy, J. Galí and M. J. Gertler, eds., Chicago: Chicago University Press, pp. 547-579.

[23] Vives, Xavier, 1990, "Trade Association Disclosure Rules, Incentives to Share Information, and Welfare," RAND Journal of Economics 21, pp. 409-430.

[24] Woodford, Michael, 2003, "Imperfect Common Knowledge and the Effects of Monetary Policy," in Knowledge, Information, and Expectations in Modern Macroeconomics: In Honour of Edmund S. Phelps, P. Aghion, R. Frydman, J. Stiglitz, and M. Woodford, eds., Princeton: Princeton University Press, pp. 25-58. 


\section{A Consumer demand under MO's preferences}

The consumers' problem is to maximize (1) subject to (2). The first-order condition is obtained as,

$$
p_{t}(j)=\alpha-\beta q_{t}(j)-\gamma \int_{j \in[0, N]} q_{t}(j) d j .
$$

By integrating $p_{t}(j)$ over $j \in[0, N]$ and dividing it by $N$, we obtain,

$$
p_{t}=\frac{1}{N} \int_{j \in[0, N]} p_{t}(j) d j=\alpha-\frac{\beta}{N} \int_{j \in[0, N]} q_{t}(j) d j-\gamma \int_{j \in[0, N]} q_{t}(j) d j
$$

Using (23), $\int_{j \in[0, N]} q_{t}(j) d j$ is eliminated from (24), resulting in the demand function given by $(3)$.

\section{B Comparative statics}

\section{B.1 The individual and equilibrium prices}

Firm j's problem given by (4) subject to (3) can be rewritten as,

$$
\max _{p_{t}(j)}:-\frac{1}{\beta} \mathbb{E}_{t}\left[\left(p_{t}(j)-p_{t}\right)^{2} r+\left\{p_{t}(j)-\left(\kappa \alpha+(1-\kappa) c_{t}\right)\right\}^{2}(1-r)\right]+\Psi,
$$

where $\Psi$ represents all exogenous terms for firm $j$. Notice that the structure of this optimization problem is exactly the same as those introduced by Morris and Shin (2002). Due to the linear-quadratic nature of the problem, the optimal price set by firm $j$ has a linear form given by,

$$
p_{t}(j)=\kappa \alpha+(1-\kappa) \phi_{t}(\lambda) \mathbf{x}_{t}(j)^{\prime}
$$

where $\phi_{t}=\left[\phi_{t} \phi_{t-1} \cdots \phi_{0}\right]$ and $\mathbf{x}_{t}(j)=\left[x_{t}(j) x_{t-1}(j) \cdots x_{0}(j)\right]$. Given the assumption that information structure converged in $t=0$, we conjecture that $\phi_{t}$ takes the following form independent of $t$ such that $\phi_{t-j}=(1-\mu) \mu^{j}$, where $\mu$ is the smaller root of $\lambda z^{2}-(1+\lambda) z+\lambda=$ 
0. Consequently, firm $j$ 's optimally chosen price should take the form,

$$
p_{t}(j)=\mu p_{t-1}(j)+(1-\mu)\left\{\kappa \alpha+(1-\kappa) x_{t}(j)\right\} .
$$

This conjecture (27) is substituted back into (25) and it can be confirmed that there exists

a unique $\mu \in[0,1]$ that solves the optimization problem. Integrating (27) over $j$ leads to the equilibrium price given by (13).

\section{B.2 Inflation persistence and market concentration: Comparative statics}

The comparative statics take three steps. First, we inspect $d \mu / d \lambda$. Because $\mu \in[0,1]$ is the smaller root of $\lambda z^{2}-(1+\lambda) z+\lambda=0$,applying the implicit function theorem leaves,

$$
\frac{d \mu}{d \lambda}=\frac{\mu}{\lambda^{2}}\left\{(1-\mu)+\left(\frac{1}{\lambda}-\mu\right)\right\}^{-1}>0 .
$$

The second step is to examine $d \lambda / d r$, which is clearly positive as shown by (15). In the third step, $d r / d h<0$ is assured by the definition of strategic complementarity given by (8). Finally, the chain rule combines the three inequalities, which results in (16).

\section{Numerical solutions of the extended model}

\section{C.1 The solution form}

We redefine the vector $\phi_{t}=\left[\phi_{t} \phi_{t-1} \cdots \phi_{0}\right]$ as,

$\phi_{t}=\arg \min _{\left\{\phi_{0}, \phi_{1}, \ldots \phi_{t}\right\}} \mathbb{E}\left[\begin{array}{c}r \sum_{s=0}^{t} \phi_{t-s}^{2} \tau^{2}+(1-r)\left\{\left(\phi_{t}-1\right)^{2} \zeta^{2}+\phi_{t}^{2} \tau^{2}+\sum_{s=1}^{\infty} \phi_{t-s}^{2}\left(\tau^{2}+\zeta^{2}\right)\right\} \\ +(1-r)\left\{\sum_{s=0}^{t}\left(\sum_{u=0}^{s} \phi_{t-u} \frac{1-\rho^{s-u+1}}{1-\rho}-\frac{1-\rho^{s+1}}{1-\rho}\right)^{2} \sigma^{2}\right\}\end{array}\right]$.

The terms in the square bracket on the right-hand side of (28) are obtained by substituting (20) and (26) into (25) under the assumptions that (i) $c_{t}$ follows the general process specified 
in (17)-(19) and (ii) information structure converged at $t=0 .^{22}$ It can be confirmed that $\left\{\phi_{t}, \phi_{t-1}, \cdots, \phi_{0}\right\}$ satisfies the following $t+1$ conditions.

$$
\begin{aligned}
\phi_{t}= & \Gamma_{1}+\Gamma_{2}(1+\rho) \phi_{t-1}-\Gamma_{2} \rho \phi_{t-2} \\
\phi_{t-s}= & \left(1-\Gamma_{2}\right)\left\{\frac{1-\rho^{s+1}}{1-\rho}-\sum_{k=1}^{s}\left(\frac{1-\rho^{s+2-k}}{1-\rho}\right) \phi_{t+1-k}\right\} \\
& +\Gamma_{2}(1+\rho) \phi_{t-s-1}-\Gamma_{2} \rho \phi_{t-s-2}
\end{aligned}
$$

for $s \in\{1,2, \ldots t-2\}$ and,

$$
\begin{aligned}
& \phi_{1}=\left(1-\Gamma_{2}\right)\left\{\frac{1-\rho^{t}}{1-\rho}-\sum_{k=1}^{t-1}\left(\frac{1-\rho^{t+1-k}}{1-\rho}\right) \phi_{t+1-k}\right\}+\Gamma_{2}(1+\rho) \phi_{0}, \\
& \phi_{0}=\left(1-\Gamma_{2}\right)\left\{\frac{1-\rho^{t+1}}{1-\rho}-\sum_{k=1}^{t}\left(\frac{1-\rho^{t+2-k}}{1-\rho}\right) \phi_{t+1-k}\right\},
\end{aligned}
$$

where,

$$
\Gamma_{1} \equiv \frac{(1-r)\left(\sigma^{2}+\zeta^{2}\right)}{r \tau^{2}+(1-r)\left(\tau^{2}+\sigma^{2}+\zeta^{2}\right)}, \quad \Gamma_{2} \equiv \frac{r \tau^{2}+(1-r)\left(\tau^{2}+\zeta^{2}\right)}{r \tau^{2}+(1-r)\left(\tau^{2}+\sigma^{2}+\zeta^{2}\right)}
$$

Then, the solution form is given by,

$$
p_{t}=\kappa \alpha+(1-\kappa) \phi_{t} \mathbf{c}_{t}^{\prime}
$$

where $\mathbf{c}_{t}=\left[\begin{array}{cccc}c_{t} & c_{t-1} \cdots & \cdots\end{array}\right]$

\section{C.2 Approximation}

When $t$ is extremely large, it is not feasible to deal with $t \times t$ matrices numerically. Therefore, we further assume that for a large $T<t$, all elements in $\left[\phi_{t-T-1} \phi_{t-T-2} \ldots \phi_{0}\right]$ should be zero. This additional assumption reduces the dimension of the matrices needed to compute the solution numerically.

Define a $1 \times(T+1)$ vector $\hat{\phi}_{t}=\left[\phi_{t} \phi_{t-1} \cdots \phi_{t-T}\right]$ which satisfies the $T+1$ conditions

\footnotetext{
${ }^{22}$ Under this assumption, $\Gamma_{1}$ and $\Gamma_{2}$ can be dealt with as constant values independent of $t$.
} 
given by (29) and (30) for $s \in\{1,2, \ldots T+1\}$. Then, $\hat{\phi}_{t}^{\prime}$ can be obtained by,

$$
\hat{\phi}_{t}^{\prime}=(\mathbf{I}-\mathbf{M})^{-1} \mathbf{G}^{\prime}
$$

where $\mathbf{I}_{(T+1) \times(T+1)}$ is an identity matrix and $\mathbf{M}_{(T+1) \times(T+1)}$ and $\mathbf{G}_{1 \times(T+1)}$ are given by,

$$
\begin{gathered}
\mathbf{M}=\left[\begin{array}{cccccc}
0 & \Gamma_{2} \frac{1-\rho^{2}}{1-\rho} & -\Gamma_{2} \rho & 0 & \ldots & 0 \\
-\left(1-\Gamma_{2}\right) \frac{1-\rho^{2}}{1-\rho} & 0 & \Gamma_{2} \frac{1-\rho^{2}}{1-\rho} & -\Gamma_{2} \rho & \ddots & \vdots \\
-\left(1-\Gamma_{2}\right) \frac{1-\rho^{3}}{1-\rho} & -\left(1-\Gamma_{2}\right) \frac{1-\rho^{2}}{1-\rho} & 0 & \ddots & \ddots & 0 \\
\vdots & \ddots & \ddots & \ddots & \ddots & -\Gamma_{2} \rho \\
\vdots & \ddots & \ddots & \ddots & 0 & \Gamma_{2} \frac{1-\rho^{2}}{1-\rho} \\
-\left(1-\Gamma_{2}\right) \frac{1-\rho^{T+1}}{1-\rho} & -\left(1-\Gamma_{2}\right) \frac{1-\rho^{T}}{1-\rho} & \ldots & -\left(1-\Gamma_{2}\right) \frac{1-\rho^{3}}{1-\rho} & -\left(1-\Gamma_{2}\right) \frac{1-\rho^{2}}{1-\rho} & 0
\end{array}\right], \\
\mathbf{G}=\left[\begin{array}{ll}
\Gamma_{1}\left(1-\Gamma_{2}\right)(1+\rho) & \left.\ldots\left(1-\Gamma_{2}\right)\left(1+\ldots+\rho^{T}\right)\right]
\end{array}\right.
\end{gathered}
$$

\section{C.3 Inflation persistence}

The inflation is now approximated by,

$$
\Delta p_{t} \simeq(1-\kappa) \hat{\phi}_{t} \Delta \hat{\mathbf{c}}_{t}^{\prime}
$$

where $\Delta \hat{\mathbf{c}}_{t}=\left[\Delta c_{t} \Delta c_{t-1} \cdots \Delta c_{t-T}\right]$. Using this approximated form, inflation persistence is calculated as follows.

$$
\operatorname{Corr}\left(\Delta p_{t}, \Delta p_{t-1}\right)=\frac{\sum_{s=0}^{T} a_{t-s} a_{t-s-1} \sigma^{2}+\sum_{s=0}^{T} b_{t-s} b_{t-s-1} \zeta^{2}}{\sum_{s=0}^{T} a_{t-s}^{2} \sigma^{2}+\sum_{s=0}^{T} b_{t-s}^{2} \zeta^{2}}
$$


where $a_{t-s}$ and $b_{t-s}$ for $s \in\{0,1,2, . . T\}$ are characterized by $\mathbf{A}^{\prime}=(\mathbf{I}-\mathbf{P})^{-1} \hat{\phi}_{t}^{\prime}$ and $\mathbf{B}^{\prime}=\mathbf{Q} \hat{\phi}_{t}^{\prime}$ given by,

$$
\begin{aligned}
\mathbf{A} & =\left[\begin{array}{llll}
a_{t} & a_{t-1} & \ldots & a_{t-T}
\end{array}\right], \\
\mathbf{B} & =\left[\begin{array}{llll}
b_{t} & b_{t-1} & \ldots & b_{t-T}
\end{array}\right], \\
\mathbf{P} & =\left[\begin{array}{ccccc}
0 & \ldots & \ldots & \ldots & 0 \\
\rho & \ddots & \ddots & \ddots & \vdots \\
0 & \rho & \ddots & \ddots & \vdots \\
\vdots & \ddots & \ddots & \ddots & \vdots \\
0 & \ldots & \ldots & \rho & 0
\end{array}\right], \text { and } \mathbf{Q}=\left[\begin{array}{ccccc}
1 & 0 & \ldots & \ldots & 0 \\
-1 & 1 & \ddots & \ddots & \vdots \\
0 & -1 & 1 & \ddots & \vdots \\
\vdots & \ddots & \ddots & \ddots & 0 \\
0 & \ldots & \ldots & -1 & 1
\end{array}\right] .
\end{aligned}
$$


Figure 1: Scatter plot of inflation persistence and market concentration

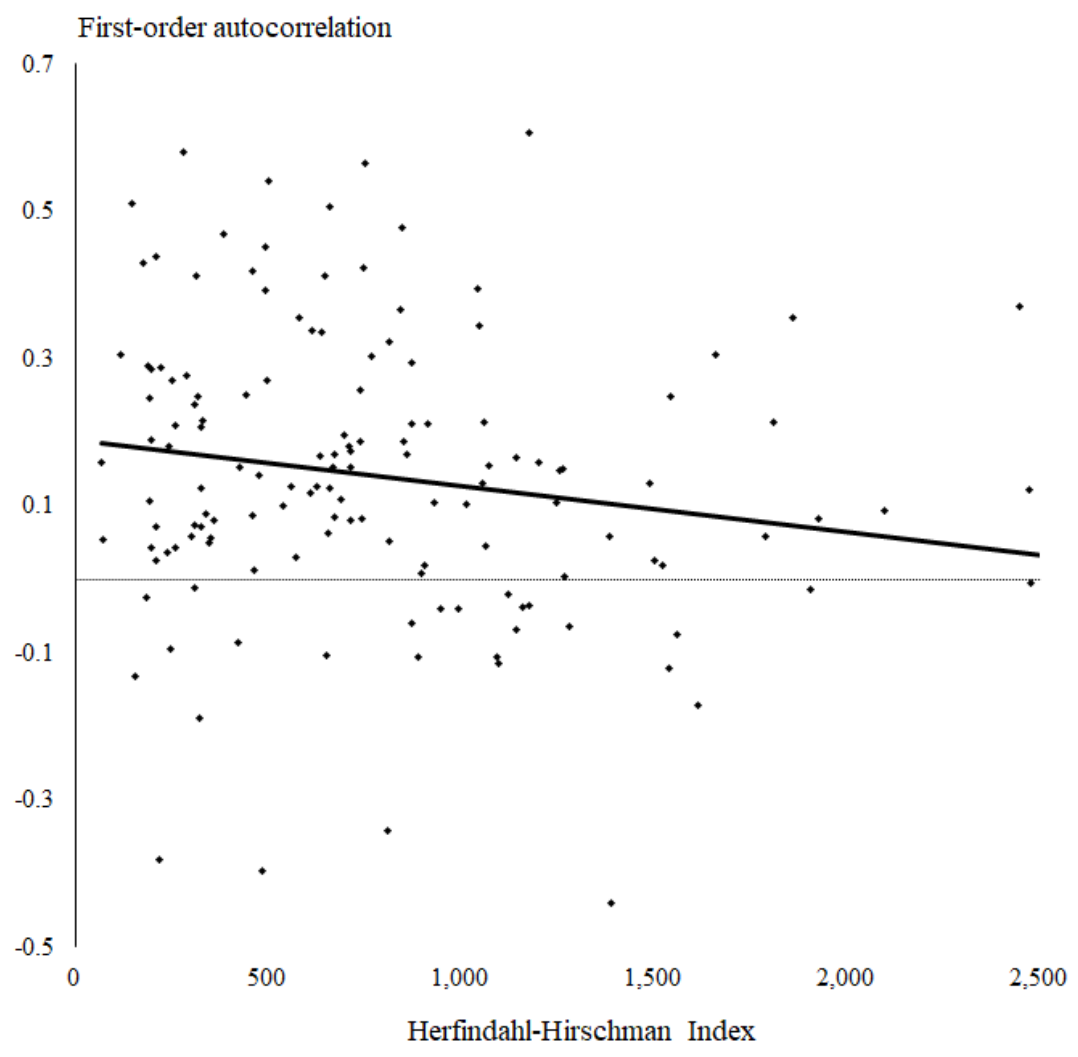

Notes: The vertical axis is inflation persistence measured by the first-order autocorrelation of the seasonally adjusted monthly difference of the sectoral (log) prices taken from BGM. The horizontal axis is the Herfindahl-Hirschman Index. 
Figure 2: Model predictions under various $\rho$
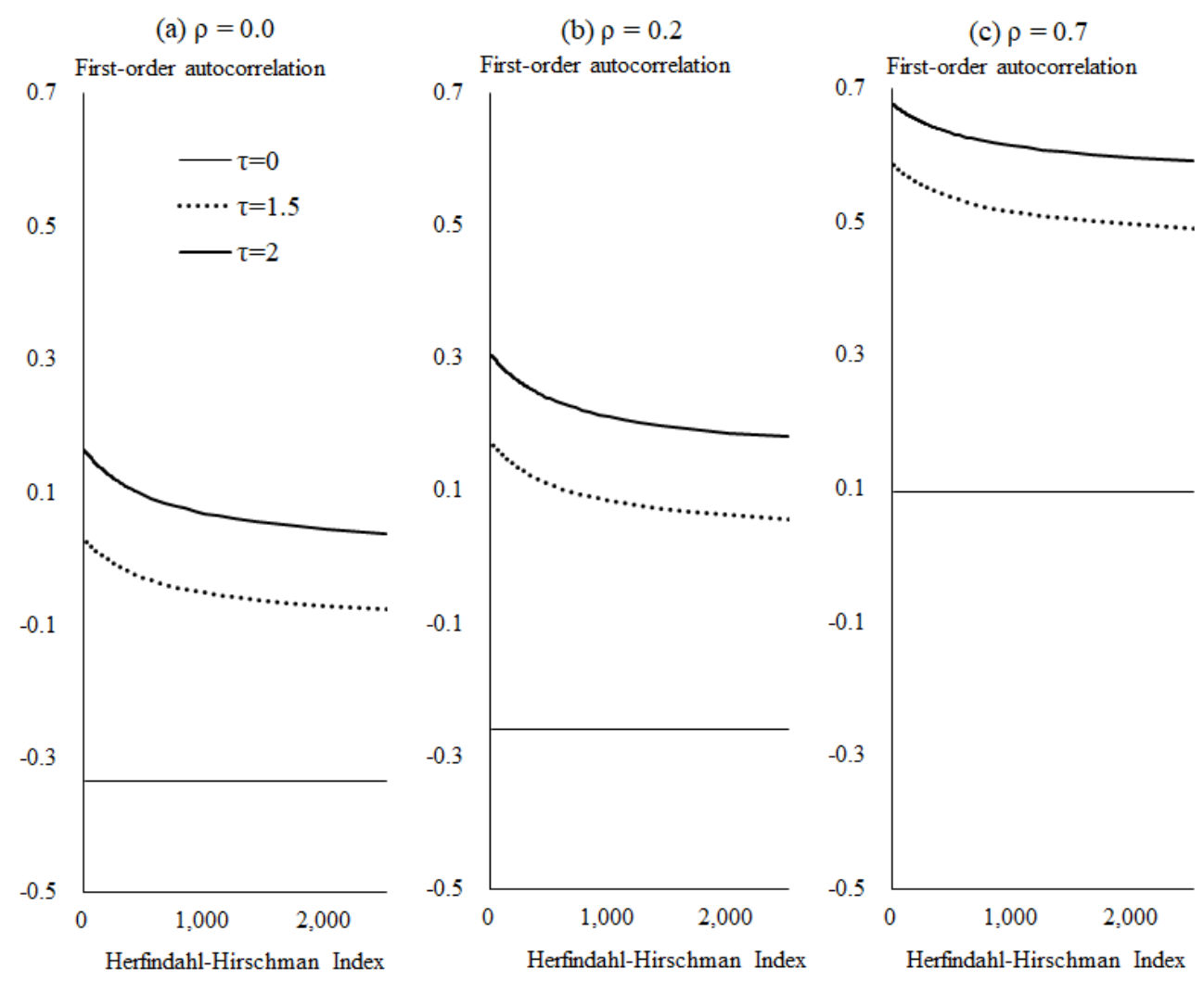

Notes: The vertical axis is inflation persistence measured by the first-order autocorrelation. The horizontal axis is the Herfindahl-Hirschman Index. 
Figure 3: Predicted size of declines in inflation persistence

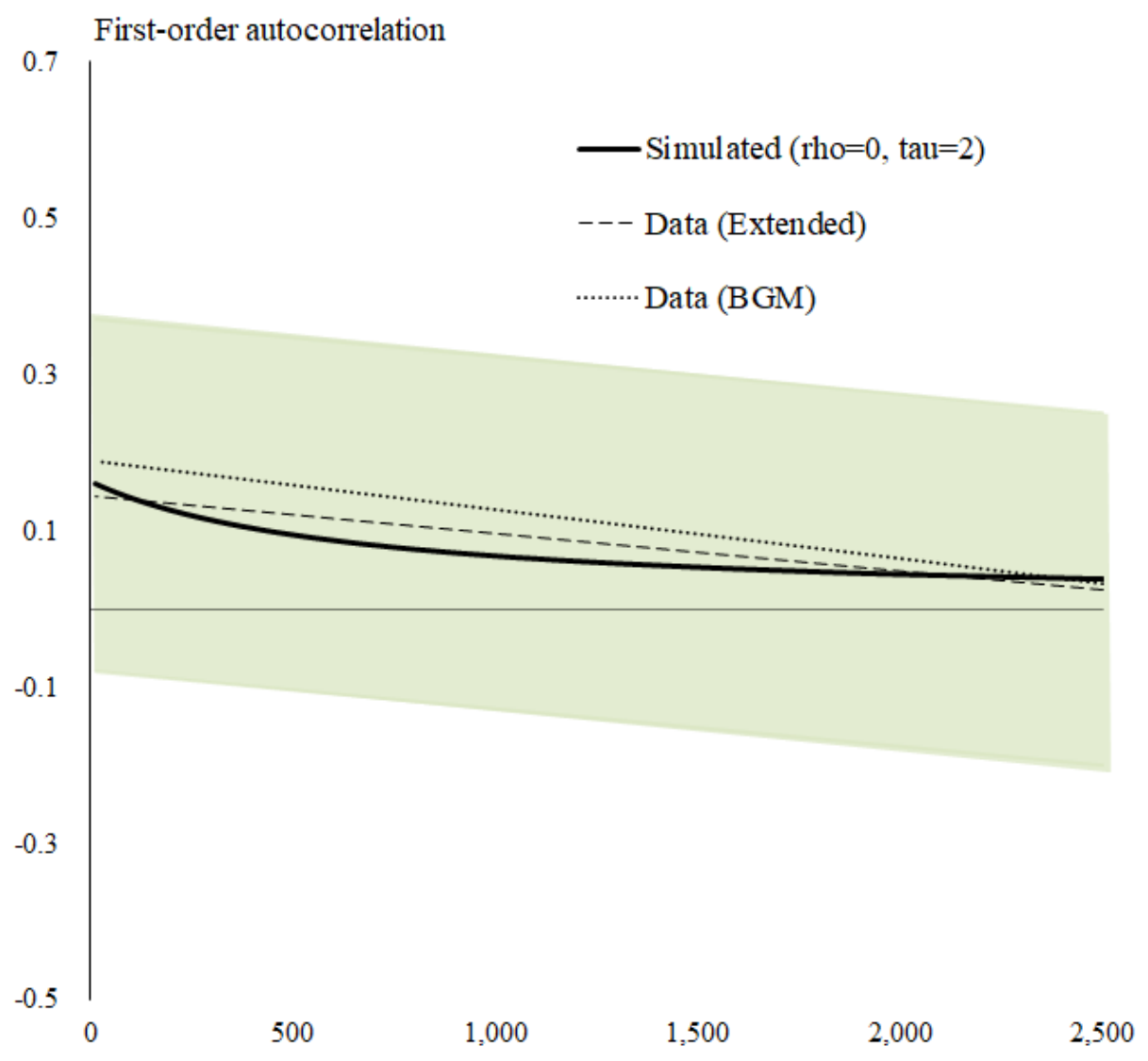

Notes: The vertical axis is inflation persistence measured by the first-order autocorrelation. The horizontal axis is the Herfindahl-Hirschman Index. The "Data" lines indicate the regression lines of specification (1-1) based on the BGM dataset and specification (2-1) based on the extended dataset in Table 2. "Simulated" indicates the prediction of the model with $\rho=0$ and $\tau=2$. The shaded area indicates the range of \pm 1 standard deviation from the regression line calculated using the residuals of regression in specification (2-1). 
Figure 4: Impulse response function of $\Delta p_{t}$

(a) Perfect Information: $\tau=0$

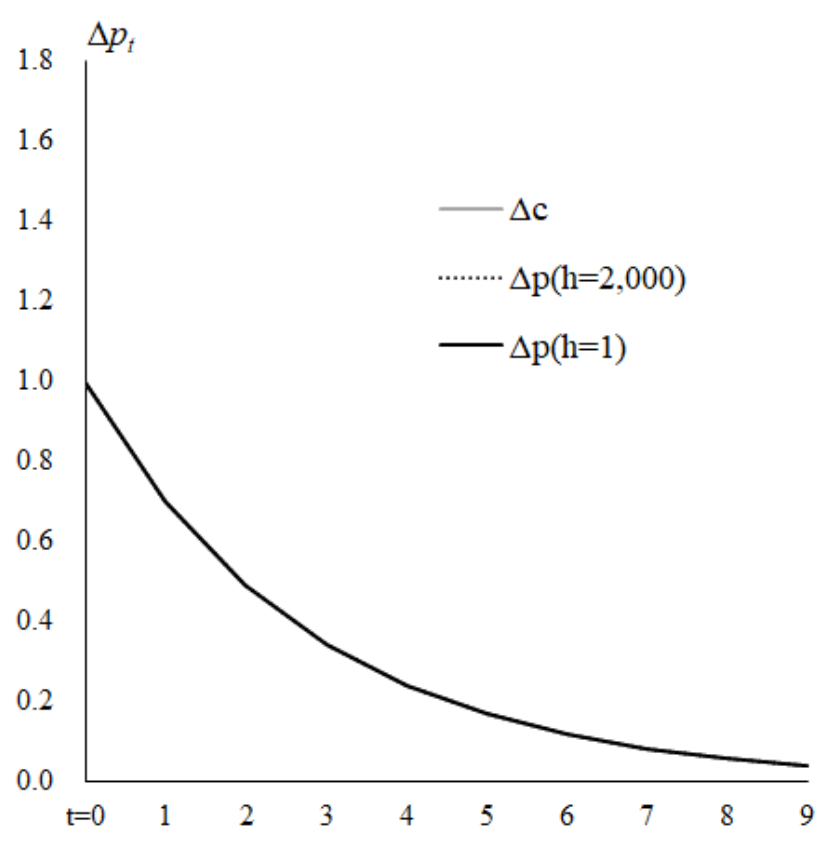

(b) Imperfect Information: $\tau=4$

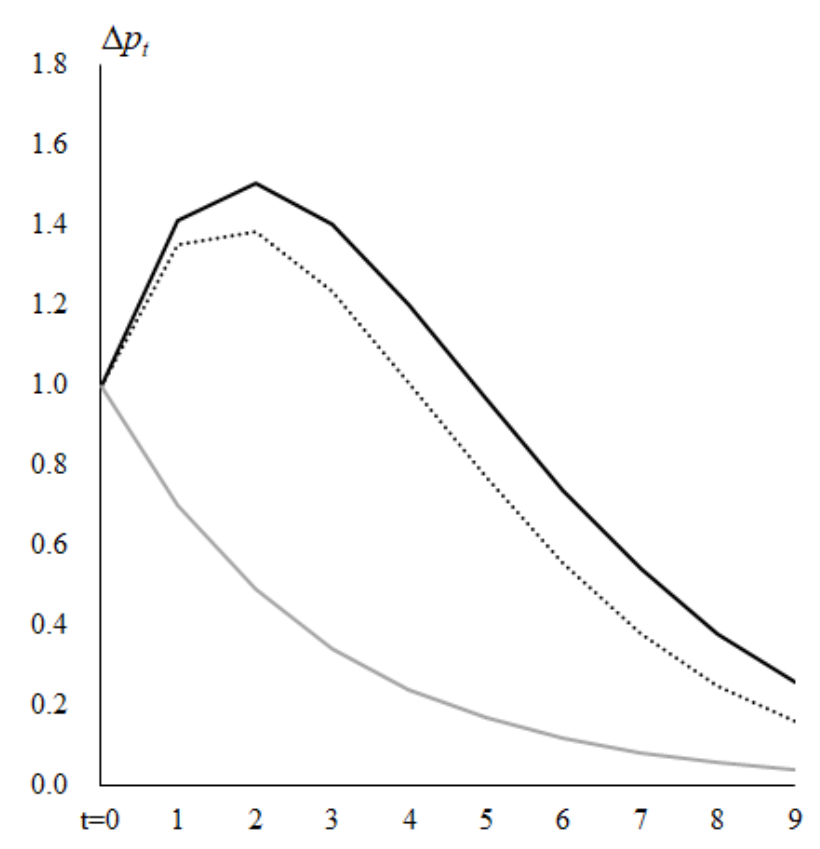

Notes: $\rho$ is set at 0.7 in both panels. 
TABLE 1: Descriptive statistics of sectoral inflation persistence ${ }^{a}$

\begin{tabular}{|c|c|c|c|}
\hline \multirow{2}{*}{$\begin{array}{l}\text { Sample Period } \\
\text { Industries }\end{array}$} & \multirow{2}{*}{$\begin{array}{c}\text { BGM dataset: } \\
\text { 1976/2M-2005/6M } \\
\text { Manufacturers }\end{array}$} & \multicolumn{2}{|c|}{$\begin{array}{l}\text { Extended dataset: } \\
\text { 2004/1M-2017/2M }\end{array}$} \\
\hline & & Manufacturers & Nonmanufacturers \\
\hline Average & 0.14 & 0.11 & -0.08 \\
\hline Median & 0.12 & 0.06 & -0.08 \\
\hline Minimum & -0.44 & -0.59 & -0.60 \\
\hline Maximum & 0.61 & 0.75 & 0.50 \\
\hline Standard Deviation & 0.19 & 0.23 & 0.18 \\
\hline Observations & 152 & 272 & 111 \\
\hline
\end{tabular}

a The inflation persistence is measured by the first-order autocorrelation estimated from an AR(1) model using seasonally adjusted monthly difference of sectoral log prices (NAICS six-digit classification). 
TABLE 2: Regression results for manufacturers: HHIa

\begin{tabular}{|c|c|c|c|c|c|c|}
\hline & \multicolumn{3}{|c|}{$\begin{array}{c}\text { BGM dataset: } \\
\text { 1974/2M-2005/6M }\end{array}$} & \multicolumn{3}{|c|}{$\begin{array}{l}\text { Extended dataset: } \\
\text { 2004/1M-2017/2M }\end{array}$} \\
\hline & $(1-1)$ & $(1-2)$ & $(1-3)$ & $(2-1)$ & $(2-2)$ & $(2-3)$ \\
\hline$H H I_{i} / 1000$ & $\begin{array}{c}-0.062^{* *} \\
(0.025)\end{array}$ & $\begin{array}{c}-0.062^{* *} \\
(0.025)\end{array}$ & $\begin{array}{c}-0.063^{* *} \\
(0.026)\end{array}$ & $\begin{array}{c}-0.048^{* *} \\
(0.022)\end{array}$ & $\begin{array}{c}-0.056^{* *} \\
(0.022)\end{array}$ & $\begin{array}{r}-0.055^{\star *} \\
(0.022)\end{array}$ \\
\hline$\sigma_{i}^{2}$ & & $\begin{array}{l}-3437.27 \\
(8097.76)\end{array}$ & & & $\begin{array}{l}9798.93^{* *} \\
(4077.45)\end{array}$ & \\
\hline DM1 & & & $\begin{array}{l}-0.072 \\
(0.039)\end{array}$ & & & $\begin{array}{l}0.085^{\star *} \\
(0.039)\end{array}$ \\
\hline DM2 & & & $\begin{array}{r}0.033 \\
(0.039)\end{array}$ & & & $\begin{array}{l}0.071^{* *} \\
(0.031)\end{array}$ \\
\hline Observations & 145 & 145 & 145 & 264 & 264 & 264 \\
\hline Adjusted- $R^{2}$ & 0.034 & 0.028 & 0.059 & 0.014 & 0.031 & 0.035 \\
\hline$F$-statistic & 6.072 & 3.109 & 3.984 & 4.663 & 5.262 & 4.156 \\
\hline$p$-value & 0.015 & 0.048 & 0.009 & 0.031 & 0.006 & 0.007 \\
\hline
\end{tabular}

a The dependent variable is the first-order autocorrelation estimated from an AR(1) model using seasonally adjusted monthly difference of the sectoral log prices. $H H I_{i}$ is the Herfindahl-Hirschman Index from the 2007 Economic Census, where $i$ denotes the industry (sector) in the data. $\sigma_{i}^{2}$ is the sample variance of the residuals of the AR(1) model. DM1 is a dummy variable controlling for food and textiles industries (NAICS codes starting with 31) while DM2 is a dummy variable controlling for paper, wood and chemicals industries (NAICS codes starting with 32). All specifications include constant terms.

*** $p<0.01$,

** $p<0.05$. 
TABLE 3: Regression results for manufacturers: C4 ratio

\begin{tabular}{|c|c|c|c|c|c|c|}
\hline & \multirow{2}{*}{\multicolumn{3}{|c|}{$\begin{array}{c}\text { BGM dataset: } \\
\text { 1974/2M-2005/6M }\end{array}$}} & \multirow{2}{*}{\multicolumn{3}{|c|}{$\begin{array}{l}\text { Extended dataset: } \\
\text { 2004/1M-2017/2M }\end{array}$}} \\
\hline & & & & & & \\
\hline & $(1-1)$ & $(1-2)$ & $(1-3)$ & $(2-1)$ & $(2-2)$ & $(2-3)$ \\
\hline$C 4_{i}$ & $\begin{array}{c}-0.194^{* *} \\
(0.081)\end{array}$ & $\begin{array}{c}-0.192^{* *} \\
(0.081)\end{array}$ & $\begin{array}{c}-0.174^{* *} \\
(0.082)\end{array}$ & $\begin{array}{c}-0.160^{* *} \\
(0.071)\end{array}$ & $\begin{array}{c}-0.199^{* * *} \\
(0.071)\end{array}$ & $\begin{array}{c}-0.185^{\star * *} \\
(0.071)\end{array}$ \\
\hline$\sigma_{i}^{2}$ & & $\begin{array}{c}1758.35 \\
(8036.54)\end{array}$ & & & $\begin{array}{c}11713.56^{* * *} \\
(3885.81)\end{array}$ & \\
\hline DM1 & & & $\begin{array}{l}-0.073 \\
(0.038)\end{array}$ & & & $\begin{array}{l}0.080^{* *} \\
(0.039)\end{array}$ \\
\hline DM2 & & & $\begin{array}{c}0.010 \\
(0.038)\end{array}$ & & & $\begin{array}{l}0.074^{* *} \\
(0.031)\end{array}$ \\
\hline Observations & 152 & 152 & 152 & 272 & 272 & 272 \\
\hline Adjusted- $R^{2}$ & 0.031 & 0.024 & 0.047 & 0.015 & 0.043 & 0.035 \\
\hline F-statistic & 5.780 & 2.895 & 3.485 & 5.068 & 7.153 & 4.287 \\
\hline$p$-value & 0.017 & 0.058 & 0.017 & 0.025 & 0.001 & 0.001 \\
\hline
\end{tabular}

${ }^{a} C_{i}$ is the market share of the top-four largest firms included in the 2007 Economic Census, where $i$ denotes the industry (sector) in the data. See the notes for Table 2 for other details.

*** $p<0.01$,

$* *<<0.05$. 
TABLE 4: Regression results for all industries: C4 ratio ${ }^{a}$

\begin{tabular}{lcccc}
\hline \hline & \multicolumn{4}{c}{ Extended dataset: 2004/1M-2017/2M } \\
& $(1)$ & $(2)$ & $(3)$ & $(4)$ \\
\hline$C 4_{i}$ & -0.080 & -0.079 & $-0.156^{* * *}$ & $-0.155^{* * *}$ \\
& $(0.057)$ & $(0.063)$ & $(0.053)$ & $(0.053)$ \\
$\sigma_{i}{ }^{2}$ & & & & \\
& & -1003.69 & & -383.47 \\
& & $(792.33)$ & & $(734.87)$ \\
DM3 & & & $0.203^{* * *}$ & $0.202^{* * *}$ \\
& & & $(0.024)$ & $(0.025)$ \\
\hline Observations & 383 & 383 & 383 & 383 \\
Adjusted- ${ }^{2}$ & 0.003 & 0.004 & 0.154 & 0.152 \\
F-statistic & 2.010 & 1.809 & 35.789 & 23.900 \\
$\quad$-value & 0.157 & 0.165 & 0.000 & 0.000 \\
\hline
\end{tabular}

a The regression results use the extended dataset covering 272 manufacturing sectors and 111

nonmanufacturing sectors from January 2004 to February 2017. DM3 is a dummy variable that controls for manufacturers. See the notes for Table 2 for other details.

$* * * p<0.01$,

** $p<0.05$. 